\title{
GESTÃO DE CUSTOS EM UMA COZINHA INDUSTRIAL DE UMA COOPERATIVA DA REGIÃO OESTE DO PARANÁ
}

\author{
Gabriela Chiele Joner ${ }^{1}$ \\ Juliane de Freitas Battisti ${ }^{2}$ \\ Reginaldo Borges ${ }^{3}$ \\ Jovani Patias ${ }^{4}$
}

\section{Resumo}

Este trabalho teve como objetivo analisar custos envolvidos na produção dos cardápios em uma cozinha industrial de uma cooperativa da região oeste do Paraná. Utilizou-se o método de custeio por absorção para identificação dos custos unitários de cada cardápio, pois este abrange maiores quantidades de elementos. O levantamento dos custos foi realizado através das informações de relatórios de controle da empresa e principalmente do acompanhamento do processo de produção dos cardápios. Através dos dados obtidos, identificou-se o custo unitário de cada cardápio e a disparidade entre eles, principalmente, entre o custo do cardápio 10 , mais barato, e do cardápio 11, mais caro, sendo uma diferença de $\mathrm{R} \$ 4,62$ (quatro reais e sessenta e dois centavos) por refeição. Com a análise da composição e os custos dos cardápios, sugeriu-se 04 (quatro) cardápios considerados como mais econômicos para a empresa. Através deste estudo, a empresa poderá utilizarse desses dados para a tomada de decisões relacionadas à alimentação dos funcionários, além de comparar quais fatores podem ser melhorados para que se consiga uma redução significativa nos custos com alimentação, refletindo em uma maior eficiência nos seus processos.

Palavras-chave: Custos. Cozinha Industrial. Custeio por Absorção.

MANAGEMENT OF COSTS IN AN INDUSTRIAL KITCHEN

OF A COOPERATIVE OF THE WEST REGION OF PARANÁ

\section{ABSTRACT}

${ }^{1}$ UTFPr

${ }^{2}$ Mestranda em Engenharia de Produção (UFSM)

${ }^{4}$ Mestra em Engenharia de Produção (UFSM)

Saber Humano-Revista Científica da Faculdade Antonio Meneghetti 
This work had the main aim to analyze the costs involved in the menu production in an industrial cuisine in a cooperative in the west region of Parana. It was used the method of upkeep for absorption to identification of unit cost for each menu, because it covers great amount of elements. The rising of costs was realized through the information from reports of the company control and specially the monitoring of the production process of the menus. Through the data gotten it was identified the unit cost for each menu and the unevenness between them. Especially between the cost of the menu 10, which is cheaper, and the menu 11 which is more expensive, having a difference of $\mathrm{R} \$ 4,62$ (four real and sixty-two cents) per meal. With the analysis of composition and the cost of menus, appeared 04 (four) menus considered as more inexpensive to the company. Through this study the company will be able to use these data to make decisions related to the feed of workers, besides, compare which factors can be enhanced to be followed a significant reduction in costs of food, reflecting in a great efficiency in their processes.

Key-words: Costs. Industrial Cuisine. Absorption Costing.

\section{Resumen}

Este trabajo tuvo como objetivo analizar costos involucrados en la producción de los menús en una cocina industrial de una cooperativa de la región oeste de Paraná. Se utilizó el método de costeo por absorción para identificación de los costos unitarios de cada menú, pues éste abarca mayores cantidades de elementos. El levantamiento de los costos fue realizado a través de las informaciones de informes de control de la empresa y principalmente del acompañamiento del proceso de producción de los menús. A través de los datos obtenidos, se identificó el costo unitario de cada menú y la disparidad entre ellos, principalmente, entre el costo del menú 10, más barato, y del menú 11, más caro, siendo una diferencia de $\mathrm{R} \$ 4,62$ (cuatro reales y sesenta y dos centavos) por comida. Con el análisis de la composición y los costos de los menús, se sugirieron 04 (cuatro) menús considerados como más económicos para la empresa. A través de este estudio, la empresa podrá utilizar estos datos para la toma de decisiones relacionadas con la alimentación de los empleados, además de comparar qué factores pueden mejorarse para que se logre una reducción significativa en los costos de alimentación, reflejando en una mayor eficiencia en sus procesos.

Palabras clave: Costes. Cocina industrial. Costeo por Absorción.

\section{INTRODUÇÃO}

Atualmente, no cenário globalizado e altamente dinâmico em que as empresas encontram-se inseridas, uma das ferramentas que auxiliam as empresas é gestão da 
produção, que tem como função principal definir um conjunto de políticas que sustente a dinamicidade da posição competitiva da empresa, com base em fatores como desempenho e programação para as áreas de decisão da produção (RITZMAN e KRAJEWSKI 2004).

A gestão da produção atua em vários ramos da indústria, como no controle de custos, onde fornece dados para o estabelecimento de padrões, orçamentos e outras formas de previsão. Também serve para acompanhar os acontecimentos em longo prazo, comparando-os com os anteriores, possibilitando projetar os gastos em produções futuras (VILANOVA e RIBEIRO, 2011).

Para controle destes custos, as organizações desenvolveram várias técnicas. Uma delas é a contabilidade de custos que, segundo Crepaldi (2004, p.13), "é uma técnica utilizada para identificar, mensurar e informar os custos dos produtos e serviços”. Dessa forma, a contabilidade de custos classifica, agrupa, registra, organiza, controla e realiza a atribuições destes. Ela é fundamental para qualquer empreendimento que deseja controlar seus gastos (BACKER e JACOBSEN, 1974).

Para cada empresa, o sistema de contabilidade de custos a ser adotado é diferente. Isso porque cada estrutura organizacional possui características próprias. De maneira geral, a contabilidade de custos possui como principal função, suprir a administração das empresas, representando, através de dados, todo montante de recursos utilizados para a execução das diversas etapas de seu processo operacional (CALLADO, 2005).

Nesse ímpeto, este trabalho visa uma maior e melhor compreensão sobre os custos em uma cozinha industrial, com o intuito de auxiliar a empresa e servir como material de apoio as novas pesquisas na área de custos em ambientes como o de estudo, frente às dificuldades na obtenção de informações sobre custos na mesma. Vale ressaltar, que uma versão deste estudo foi apresentado junto ao IX Encontro Nacional de Difusão Tecnológica - ENDITEC, promovido pela Universidade Tecnológica Federal do Paraná, Câmpus Medianeira - Medianeira, PR, Brasil.

\section{MATERIAIS E MÉTODOS}


A empresa em estudo possui, em média, 400 funcionários, que realizam suas refeições no local. Assim, a mesma conta com uma cozinha industrial para preparo das refeições. O levantamento dos custos se deu por análise de notas ficais, conversa com os responsáveis do setor, planilhas de custos gerais da unidade, além da observação do processo de elaboração das refeições.

Os meses analisados foram de maio a julho. A quantidade de refeições varia de um mês para outro por fatores como a terceirização de alguns serviços, escalas de férias dos funcionários e da rotatividade de mão-de-obra que é mais significativa em alguns meses. A pesquisa foi classificada, do ponto de vista do seu objetivo, como uma pesquisa Quantitativa, Qualitativa e Exploratória.

A coleta de dados se deu através de análise documental, análise do conteúdo dos documentos e notas fiscais e coleta de informação com pessoas diretamente ligadas as áreas da pesquisa, visando sempre à exatidão das informações. Para análise dos dados coletados, utilizou-se a comparação dos valores dos cardápios e o sistema de custeio por absorção foi o método aplicado. Este método consiste na atribuição de todos os gastos que possuem relação com o esforço de fabricação dos produtos, sejam eles acabados ou não (MARTINS, 2000).

Dessa forma, considerou-se que este método seria o mais adequado. Para tanto, realizou-se o levantamento de todos os dados referentes à elaboração dos cardápios, e posteriormente compararam-se os resultados, de forma a se obter qual o custo total de cada cardápio e quais os fatores que mais interferiram neste custo.

\section{RESULTADO E DISCUSSÃO}

O início do levantamento dos dados se deu pela identificação dos cardápios realizados mensalmente, observou-se que a empresa possui 12 cardápios os quais são servidos todos os dias da semana. A descrição dos cardápios é apresentada no Quadro 1. 
Quadro 1 - Cardápios Atuais

\begin{tabular}{|c|c|c|c|}
\hline 1 & 2 & 3 & 4 \\
\hline Feiião & Feiião & Feiião & Feiião \\
\hline Arroz & Arroz & Arroz & Arroz \\
\hline Frango à passarinho & Bisteca suína empanada & Costela bovina & Peixe \\
\hline Abobrinha refogada & Batata & Batata doce & Caniiauinha \\
\hline Pimentão & Beterraba & Couve-flor/cenoura & Cenoura/beterraba \\
\hline Almeirão & Acelga & Almeirão & Repolho \\
\hline Maçã & Pêra & Tangerina & Larania \\
\hline Suco & Suco & Suco & Suco \\
\hline 5 & 6 & 7 & 8 \\
\hline Feiião & Feiião & Feiião & Feiião \\
\hline Arroz & Arroz & Arroz & Arroz \\
\hline Peito empanado & Carne moída & Linguiça & Bife ao molho \\
\hline Maionese & Pão & Macarrão & Polenta \\
\hline Alface & Tomate & Pepine & Chicória \\
\hline Banana & Chicória & Almeirão & Tomate \\
\hline & Mamão & Caqui & Larania \\
\hline Suco & Suco & Suco & Suco \\
\hline 9 & 10 & 11 & 12 \\
\hline Feiião & Feiião & Feiião & Feiião \\
\hline Arroz & Arroz & Arroz & Arroz \\
\hline Costela suína & Coxa/sobre coxalfrangol & Paleta suína & Lasanha \\
\hline Mandioca & Renolho refogado & Maionese & \\
\hline Abobrinha/cenoura & Alface & Alface & Alface \\
\hline Repolho & Vagem & & Chuchu \\
\hline Sagu & Melão & Pudim & $\begin{array}{l}\text { Banana } \\
\text { Suco }\end{array}$ \\
\hline
\end{tabular}

Fonte: Dados da Pesquisa

Para a produção dos cardápios mencionados no Quadro 1 foi necessário 0 levantamento de todos os custos envolvidos no processo. O primeiro item observado foi o consumo de gás de cozinha, o qual é fornecido semanalmente por uma empresa da região que realiza o abastecimento dos cilindros. No total, a cozinha utiliza 20 unidades mensalmente.

A energia elétrica também influencia nos custos de cada refeição dessa forma, realizou-se seu levantamento. Como a energia que é fornecida a cozinha esta interligada com os demais setores, o levantamento foi realizado através de verificação do manual dos equipamentos, determinando o gasto individual por equipamento. Existem ainda os custos com manutenção e depreciação.

Os custos com manutenção são determinados de acordo com a necessidade de cada mês. Já os custos com depreciação são determinados por equipamento. Na cozinha, a depreciação ocorre num período de 10 anos. Para se estipular os valores mensais, utilizou-se o custo total pago pelos equipamentos e efetuou-se a divisão proporcional a 120 meses (10 anos).

Outro custo importante no processo está relacionado com a mão-de-obra, neste caso, as cozinheiras e a pessoa responsável por comprar os insumos. Para as cozinheiras 
considerou-se o valor do salário mensal e encargos das 8 cozinheiras e líder do setor. Os custos mensais dos itens relacionados acima se encontram descritos na Tabela 1.

Tabela 1 - Custos Mensais Envolvidos na Cozinha

\begin{tabular}{l|llllll}
\hline Meses/Custos & Energia & Gás & Manutenção & Depreciação & Cozinheiras & Compras \\
\hline Maio & 378,10 & 3400 & 135,2 & 580,5 & 20233,44 & 121,37 \\
Junho & 378,10 & 3400 & 128,7 & 568,9 & 20233,44 & 121,37 \\
Julho & 378,10 & 3400 & 169,7 & 573,6 & 20233,44 & 121,37 \\
\hline
\end{tabular}

Fonte: Dados as Pesquisa

$\mathrm{Na}$ Tabela 1, o custo relativo ao setor de compras é proporcional. Isso porque as compras para a cozinha utilizam apenas $4,55 \%$ do tempo mensal que esse funcionário possui para realização das compras para a empresa. Conhecendo estes custos, podemos aloca-los ao total de refeições servidas mensalmente, conhecendo, dessa forma, quanto cada um desses custos representa em uma refeição (total geral mensal). Desta forma tem-se a Tabela 2 .

Tabela 2 - Custo por Refeição Mensal

\begin{tabular}{l|cc}
\hline Meses & $\begin{array}{c}\text { Quantidade } \\
\text { de Refeições }\end{array}$ & $\begin{array}{c}\text { Total Geral Mensal por } \\
\text { Refeição }\end{array}$ \\
\hline MAIO & 9.499 & 2,62 \\
JUNHO & 8.556 & 2,90 \\
JULHO & 8.987 & 2,77 \\
\hline
\end{tabular}

Fonte: Dados da Pesquisa

Determinou-se ainda, o custo de cada cardápio em relação aos insumos utilizados. A Tabela 3 apresenta esses valores.

Tabela 3 - Custos com Cardápio em Relação aos Insumos

\begin{tabular}{l|cccccccccccc}
\hline Cardápio & 1 & 2 & 3 & 4 & 5 & 6 & 7 & 8 & 9 & 10 & 11 & 12 \\
\hline$(\mathrm{R} \$)$ & 6,94 & 7,57 & 7,91 & 8,46 & 7,09 & 6,73 & 6,47 & 5,91 & 8,06 & 4,79 & 9,41 & 6,88 \\
\hline
\end{tabular}

Fonte: Dados da Pesquisa

A partir do levantamento de todos os custos que norteiam a cozinha e a preparação das refeições, pode-se visualizar o custo total de cada cardápio, conforme mostra a Tabela 4.

Tabela 4 - Custo Total de Cada Cardápio 


\begin{tabular}{ccrrrr}
\hline Cardápios & $\begin{array}{c}\text { Custo dos insumos } \\
\text { (RS) (tabela 3) }\end{array}$ & $\begin{array}{c}\text { Custos mensais } \\
\text { (RS) (tabela 2) }\end{array}$ & $\begin{array}{c}\text { Total geral } \\
\text { (RS) }\end{array}$ & $\begin{array}{c}\text { Valor pago/ } \\
\text { funcionário } \\
\text { (RS) }\end{array}$ & $\begin{array}{c}\text { Valor pago/ } \\
\text { empresa } \\
\text { (RS) }\end{array}$ \\
\hline $\mathbf{1}$ & 6,94 & 2,76 & 9,70 & 1,27 & 8,43 \\
$\mathbf{2}$ & 7,57 & 2,76 & 10,33 & 1,27 & 9,06 \\
$\mathbf{3}$ & 7,91 & 2,76 & 10,67 & 1,27 & 9,40 \\
$\mathbf{4}$ & 8,46 & 2,76 & 11,22 & 1,27 & 9,95 \\
$\mathbf{5}$ & 7,09 & 2,76 & 9,85 & 1,27 & 8,58 \\
$\mathbf{6}$ & 6,73 & 2,76 & 9,49 & 1,27 & 8,22 \\
$\mathbf{7}$ & 6,47 & 2,76 & 9,23 & 1,27 & 7,96 \\
$\mathbf{8}$ & 5,91 & 2,76 & 8,67 & 1,27 & 7,40 \\
$\mathbf{9}$ & 8,06 & 2,76 & 10,82 & 1,27 & 9,55 \\
$\mathbf{1 0}$ & 4,79 & 2,76 & 7,55 & 1,27 & 6,28 \\
$\mathbf{1 1}$ & 9,41 & 2,76 & 12,17 & 1,27 & 10,90 \\
$\mathbf{1 2}$ & 6,88 & 2,76 & 9,64 & 1,27 & 8,37 \\
\hline
\end{tabular}

Fonte: Dados da Pesquisa.

Como "custos mensais", utilizou-se uma média dos custos analisados nos meses de maio a julho (tabela 1). Através de análise da Tabela 4, pode-se perceber que os cardápios mais barato (10) e mais caro (11) se distanciam significativamente. Cada funcionário paga $\mathrm{R} \$ 1,27$ por refeição. Esse valor foi determinado através de acordo da empresa juntamente com o sindicado dos trabalhadores. Através de análise dos resultados, sugere-se 4 cardápios, cujo custo é relativamente menor que os apresentados até aqui. O Quadro 2 detalha os cardápios sugeridos.

Quadro 2 - Cardápios Sugeridos

\begin{tabular}{|l|l|l|l|}
\hline \multicolumn{1}{|c|}{$\mathbf{2}$} & \multicolumn{1}{c|}{$\mathbf{3}$} & \multicolumn{1}{c|}{$\mathbf{4}$} \\
\hline Feijão & Feijão & Feijão & Feijão \\
\hline Arroz & Arroz & Arroz & Arroz \\
\hline Bife ao molho & Coxa/sobre coxa(frango) & Peito empanado(frango) & Linguiça \\
\hline Canjiquinha & Macarrão & Mandioca & Batata doce \\
\hline Vagem/cenoura & Acelga & Chuchu/abobrinha & Couve-flor/cenoura \\
\hline Tomate & Beterraba & Pepino & Pimentão \\
\hline Banana & Laranja & Tangerina & Laranja \\
\hline Suco & Suco & Suco & Suco \\
\hline
\end{tabular}

Fonte: Dados da Pesquisa.

Os custos com os cardápios sugeridos pagos pela empresa são descritos na tabela 5. Nesses custos já estão inclusos todos os demais custos levantados e apresentados anteriormente.

Tabela 5 - Custo década cardápio para empresa

\begin{tabular}{rrrrr}
\hline $\mathbf{1}$ & $\mathbf{2}$ & $\mathbf{3}$ & \multicolumn{1}{c}{$\mathbf{4}$} \\
\hline 6,68 & 5,11 & 7,12 & 6,83 \\
\hline
\end{tabular}

Fonte: Dados da Pesquisa. 


\section{CONSIDERAÇÕES FINAIS}

Neste trabalho apresentou-se a metodologia utilizada para levantamento dos custos nos cardápios de uma cozinha industrial de uma cooperativa da região oeste do Paraná. Observou-se a partir dos resultados obtidos com o rateio dos custos envolvidos, que a disparidade entre o cardápio 10 e 11, mais caro e mais barato, respectivamente é de $\mathrm{R} \$ 4,62$, além de se realizar o levantamento dos demais custos com o intuito de terem seus custos reduzidos.

Apresentou-se ainda uma sugestão de quatro cardápios, cujo custo é relativamente baixo, se comparado aos atuais. O sistema de custeio proposto nesta pesquisa oferece uma estrutura para a contabilização dos custos dentro de qualquer cozinha industrial, as quais seguem o mesmo processo produtivo e somente variam as matérias-primas, cardápios e equipamentos.

A sistemática proposta neste trabalho apresenta grande importância, pois serve de auxílio para o controle dos custos com as refeições servidas, além da melhoria no planejamento futuro proporcionando um equilíbrio entre as refeições e seus respectivos custos. Deve-se destacar ainda que o potencial de uso do sistema de custeio em cozinhas industriais é inexplorado, e que estudos desse tipo contribuem para a melhoria nas tomadas de decisões dentro desse setor nas empresas. Com base na conclusão desse trabalho, pode se afirmar que essas informações são importantes para a melhoria no processo de elaboração dos cardápios e contribuem para a tomada de decisão.

\section{REFERÊNCIAS}

RITZMAN, L. P.; KRAJEWSKI, L. J. Administração da Produção e Operações. $2^{\circ}$ ed. São Paulo: Pearson Education do Brasil, 2004.

VILANOVA, J. DE A.; RIBEIRO, C.F. Importância da gestão da produção e gerenciamento de custos em uma indústria alimentícia. Instituto Brasileiro de profissionais de Supply Chain. Artigo 301. Fevereiro, 2011.

CREPALDI, Sílvio Aparecido. Curso Básico de Contabilidade de Custos. 3. ed. São Paulo: Atlas, 2004.

BACKER, M.; JACOBSEN, L. E. Contabilidade de custos: um enfoque para administração de empresas. São Paulo: MacGraw-Will do Brasil, 1974.

CALLADO, Aldo L. C. Gestão de custos: apresentação de um modelo quantitativo sobre custos indiretos de produção. Biblioteca online SEBRAE, janeiro de 2005. Disponível

em: 
<http://bis.sebrae.com.br/GestorRepositorio/ARQUIVOS_CHRONUS/bds/bds.nsf/AB B45EF6 55DF0B8E83256F6B00638CCE/\$File/NT0003040A.pdf >. Acesso em: 05 mar. 2013

MARTINS, Eliseu. Contabilidade de custos. 7 ed. São Paulo: atlas, 2000. 